\title{
PROPERTIES OF BACTERIAL CELLULOSE AND ITS INFLUENCE ON THE PHYSICAL PROPERTIES OF PAPER
}

\author{
Wen-Hua Gao, Ke-Fu Chen, Ren-Dang Yang,* Fei Yang, and Wen-Jia Han \\ Bacterial cellulose is a promising source of biodegradable polymers \\ having high purity. The time required to disperse bacterial cellulose wet \\ membranes was studied, along with evaluation by infrared spectroscopy \\ and thermal analysis of the dispersed bacterial fiber and tests of the \\ physical properties of the sheet. The results showed that bacterial \\ cellulose wet membrane can be dispersed well, forming fibers when the \\ dispersing time was 3 minutes at a suitable concentration. FT-IR results \\ showed that the composition of bacterial fiber is similar to that of \\ bleached softwood fibers. Thus, the morphology, thermal performance, \\ and the length of bacterial fibers are significantly different. The sheets' \\ physical properties show that with the increasing dosage of bacterial \\ fibers (relative to softwood fiber), the properties of tensile index, tear \\ index, burst index, and stiffness greatly improve, while the porosity and \\ the relative water absorption decrease.
}

Keywords: Bacterial fibers; Fiber morphology; FT-IR analysis; Thermal analysis; Physical properties of paper

Contact information: State Key Lab of Pulp and Paper Engineering, South China University of Technology; Guangzhou, China, 510640)*Corresponding author: rdyang@scut.edu.cn

\section{INTRODUCTION}

As global resources face shortages, especially in the case of non-renewable resources, an interesting biomaterial currently under study is bacterial cellulose (BC), which can be generated by Gluconacetobacterxylinum. This material is commonly produced as a hydrated membrane or pellicle at the air-medium interface (Jonas 2002; Martins et al. 2009). Membrane morphology depends on the shape of this interface, which may easily be manipulated or controlled. The bacterial cellulose membrane exhibits excellent mechanical strength and high surface area when compared to plantderived cellulose (Vandamme 1998; Budhiono et al. 1999; Masaoka et al. 1993; Keshk 2006; Sokolnicki 2006; Wong 2009), due to the highly crystalline structure and reduced fiber diameter. Its unique structural features and properties facilitate diverse applications ranging from wound-dressing, acting as a carrier for mammalian cell culture, immobilization of enzymes and other biomolecules, to diaphragms in speakers for audiocommunication (Ramana et al. 2000; Singh et al. 1996). Furthermore, bacterial cellulose membranes have been utilized in combination with palladium to produce experimental fuel cells for the generation of electricity (Dubey et al. 2002; Evans et al. 2003; Gindl et al. 2004).

The crystallographic form of the bacterial cellulose within wet membranes has been revealed to be almost the same as that of cellulose I, which is commonly found in 
plant fiber (Jonas and Farad 1998), and the molecular orientation is believed to be parallel to the direction of the fibrils. Therefore, one can reasonably assume that it may be suitable for use in the pulp and paper industry, where its special structure and properties have potential to improve paper's performance. Flame-retardant bacterial cellulose can be used to make fire resistant paper. And by adding this style of bacterial cellulose, the physical properties of fire-resistant paper can also be improved (Basta and El-Saied 2009).

Due to the high strength of bacterial cellulose in the form of a wet membrane, it is relatively difficult to convert it to "pulp". The dispersing conditions are very important, and high-speed mechanical dispersion is a common method (Liu et al .2007). By virtue of bacterial fibers' high modulus and low density, the sheet is expected to be useful for industrial purposes, such as in specialty paper grades, as will be described. It is also expected that bacterial cellulose may partly replace plant fiber in the pulp and paper industry, as a green energy-saving material.

\section{EXPERIMENTAL}

\section{Materials}

Bacterial cellulose (BC) wet membranes, which had been produced by Gluconacetobacterxylinus from Hesterin medium, were obtained from a scientific research institution in China. Softwood pulp and direct black dye were obtained from a mill in Guangzhou.

\section{BC Wet Membranes Dispersion}

The BC membranes were rinsed several times with distilled water until a neutral $\mathrm{pH}$ was attained in the drained water. Then the membranes were torn to pieces, a procedure that is beneficial for dispersion. A high-speed dispersion machine was used to separate the $\mathrm{BC}$ pieces at the speed $11000 \mathrm{revs} / \mathrm{min}$ at a suitable concentration. If the dispersion concentration was low, the $\mathrm{BC}$ fiber ribbons easily became wrapped around the rotor winding and were not converted into individual fibers. However, if the concentration was too high, the rotor turned with difficultly, and this influenced the dispersing effect. In sum, dispersion concentration of BC membranes $(\mathrm{m} / \mathrm{m})$ was $0.3 \%$. The dispersing time was 1.5, 3, and 5 minutes, respectively.

\section{Characterization of BC Fibers}

$\mathrm{BC}$ fibers were stained by direct black dye at the $\mathrm{pH}$ level of 7 to 9 . Meanwhile, the softwood fibers were stained by He-type dye. Stained fibers were all observed by optical microscopy morphology (Olympus BX51).

Fourier transform infra-red (FT-IR) spectroscopy was performed using a Nexus Vector spectrometer made by Thermo Nicolet at room temperature. Bacterial fibers and softwood fibers were scanned using a diffuse reflectance mode, with the DRIFT sample accessory, from $4000 \mathrm{~cm}^{-1}$ to $500 \mathrm{~cm}^{-1}$. The data were collected over 64 scans with a resolution of $4 \mathrm{~cm}^{-1}$. 
Thermogravimetric analysis (Universal V1·7F TGA) was carried out, recording the fiber weight variation with different temperatures. The analysis required about $10 \mathrm{mg}$ each of $\mathrm{BC}$ fibers and softwood fibers. Under nitrogen atmosphere, the heating rate was set $t 010^{\circ} \mathrm{C} / \mathrm{min}$. Then the temperature was heated from $30{ }^{\circ} \mathrm{C}$ to $700{ }^{\circ} \mathrm{C}$. A weight loss curve and its derivative curve were thus obtained.

A Kajaani FS300 analyzer was used for characterizing fiber morphology. The length, width, kink index, and curl index of BC fibers and softwood fibers were obtained.

The scanning electron microscope (S3700) was made by Hitachi of Japan. BC fibers and softwood fibers were formed into a sheet, and SEM was able to observe the fibers clearly in that form. In particular, this approach made it possible to analyze both the position and morphology of fibers.

\section{Making Paper}

Dry-lap softwood pulp sheets were dispersed with a standard pulp-disintegrator at the consistency of $1 \%(\mathrm{~m} / \mathrm{m})$. Adding a certain dosage dispersed bacterial fibers in softwood pulp, handsheets were prepared at basis weight $70 \mathrm{~g} / \mathrm{m}^{2}$. The dosage of bacterial fibers (relative to absolute dry softwood fiber) was as follows: $1 \%, 2 \%, 3 \%, 4 \%$, and $5 \%$. The handsheets were equilibrated at constant temperature and humidity for 24 hours. According to TAPPI standards testing, physical properties of handsheets were tested, including tensile index, tear index, burst index, stiffness, permeability, and water absorption.

\section{RESULTS AND DISCUSSION}

\section{Characterization of Dispersed BC Fiber}

As shown in Fig.1, the surface of BC fibers consisted of entangled fibrils. On the fibril surfaces there were many small filaments. Therefore, the morphology differed from that of common plant fibers. The filaments can be woven with plant fibers, and formed into many combinations.

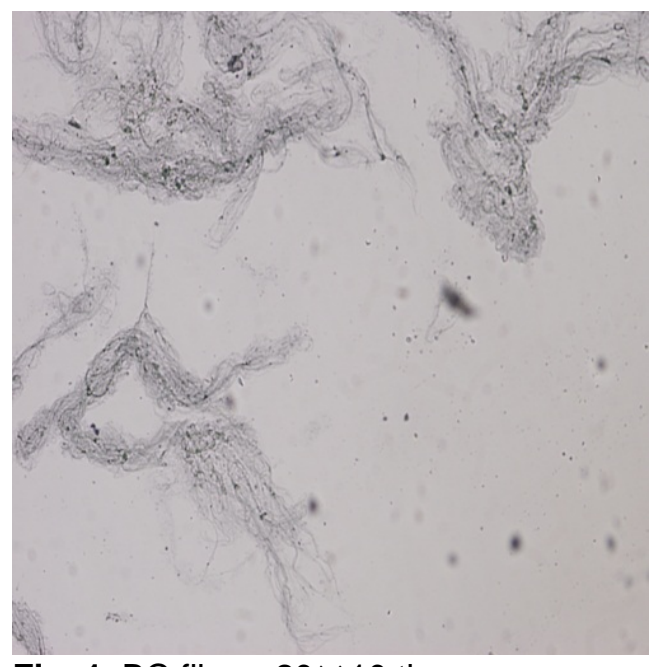

Fig. 1. $B C$ fibers $20 \times 10$ times

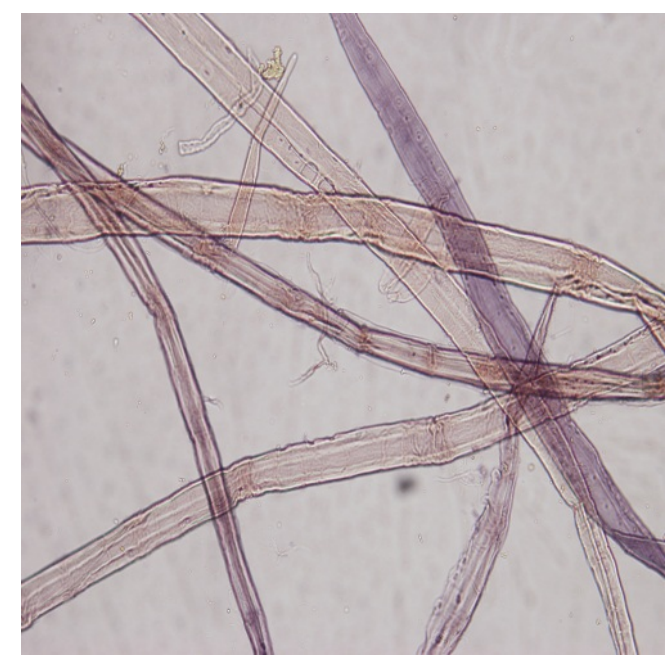

Fig. 2. Softwood fibers $20 \times 10$ times 
As shown in Fig. 2, the stained softwood fiber exhibited a typical of plant fiber appearance, which entails a spindle structure. Its surface was smooth, and the outline was clear. The use of a combination of fibers having such contrasting morphologies is expected to offer unique opportunities.

\section{FT-IR Analysis}

FT-IR spectra showed that the composition of BC fibers was similar to that of softwood fibers after bleaching. The spectra showed absorptions around $1054 \mathrm{~cm}^{-1}, 1106$ $\mathrm{cm}^{-1}$, and $3400 \mathrm{~cm}^{-1}$ stretching bands, which were attributable to R-OH. The characteristic absorption around $1400 \mathrm{~cm}^{-1}$ was attributed to a scissoring vibration of $-\mathrm{CH}$. The absorption peak at $1643 \mathrm{~cm}^{-1}$ was due to the adsorption of water on the samples. In the spectra of softwood fibers, the peaks at $1537 \mathrm{~cm}^{-1}$ and $1270 \mathrm{~cm}^{-1}$ were the characteristic absorption bands for $\mathrm{C}=\mathrm{O}$ and $-\mathrm{O}-\mathrm{R}$ of hemicellulose. And the absorption peak at 1030 $\mathrm{cm}^{-1}$ came from the groups of $-\mathrm{OCH}_{3}$, due to the residual lignin in the bleached softwood fibers. The crystallinity index was obtained from IR-spectra (A1372 $\mathrm{cm}^{-1} / \mathrm{A} 2900 \mathrm{~cm}^{-1}$ ), and the crystallinity index of BC fiber was a little bigger than that of bleached softwood fiber. In sum, it can be concluded that the special properties of bacterial fiber derive from the internal ultra-fine network structure.

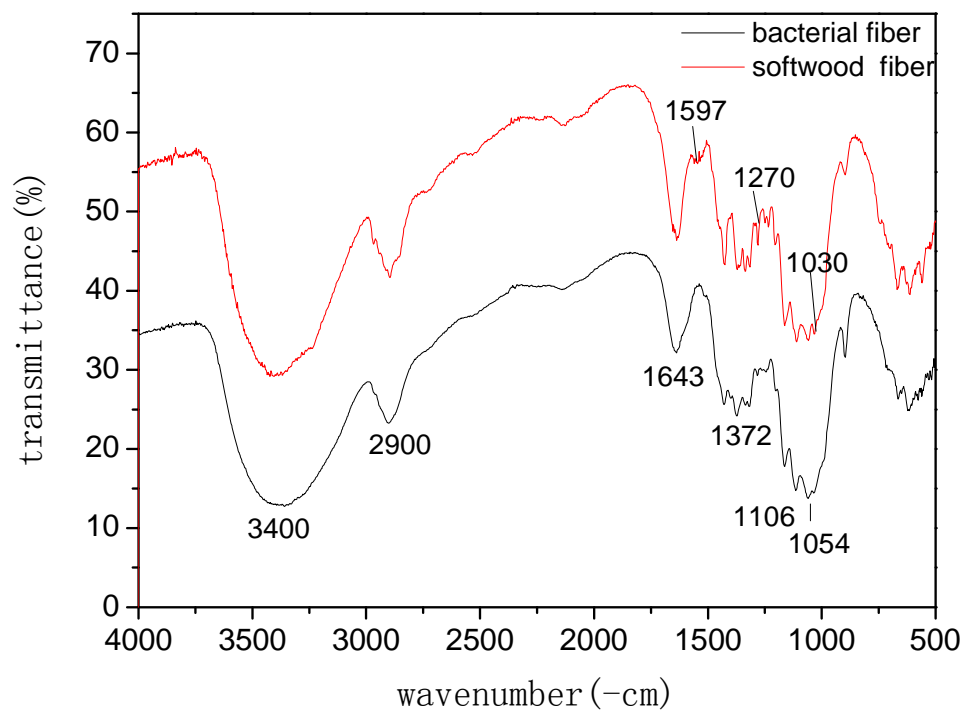

Fig. 3. FT-IR spectra of BC fibers and softwood fibers

\section{TGA Analysis}

Compared tosoftwood fibers, BC fibers have many special properties. Its TGA analysis was as follows:

As Figs. 4 and 5 show, with increasing temperature the weight of BC fibers decreased slowly at first. As the temperature rose from ambient to $200^{\circ} \mathrm{C}$, fibers desorbed the physically absorbed water. Such water was mainly associated with the amorphous areas, and crystalline areas generally did not absorb water. The internal structure of BC fiber was more compact than that of softwood fiber, so the physically adsorbed water 
gradually decreased. When the temperature continued to rise up to $250^{\circ} \mathrm{C}$, fiber physically adsorbed water became almost nonexistent. However, in the internal fiber, glucose molecules were rearranged, and the degree of polymerization obviously decreased. In the above process, the weight decrease of the two fibers was small, with the changes mainly attributable to the formation of carbonyl and carboxyl groups, in addition to the evaporation of water, and the release of carbon dioxide and carbon monoxide. The presence of oxygen played an important role.

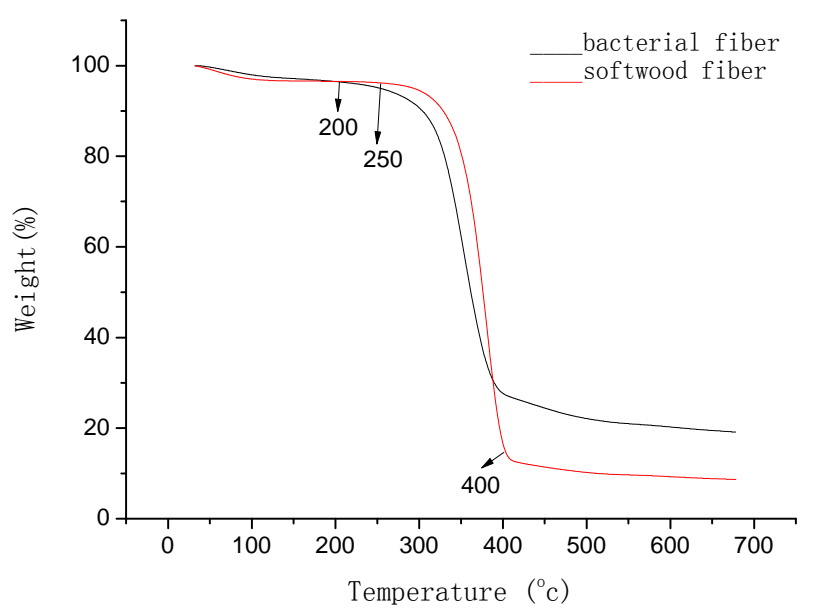

Fig. 4. TGA analysis curve of bacterial fiber and softwood fiber

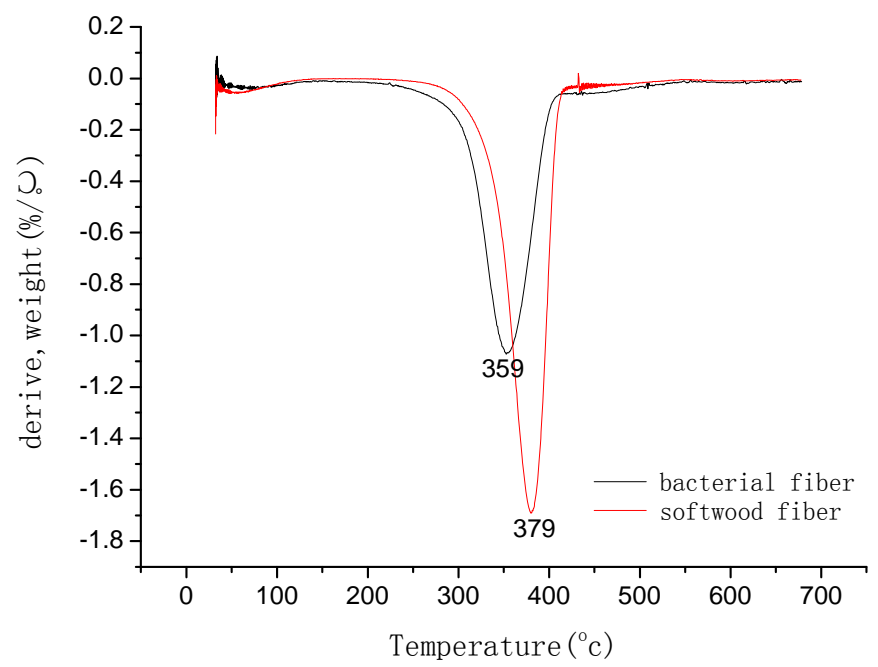

Fig. 5. DTG analysis curve of bacterial fiber and softwood fiber

Within the range of $250{ }^{\circ} \mathrm{C}$ to $400{ }^{\circ} \mathrm{C}$, glycosidic bonds within the fiber began to break, especially $\mathrm{C}-\mathrm{O}$ bonds and $\mathrm{C}-\mathrm{C}$ bonds, and new products and small molecular weight volatile compounds were produced. The fibers' weight and degree of polymerization decreased rapidly, and the crystallinity was severely damaged. Figure 5 
shows that the rate of weight reduction of BC fibers was lower than that of softwood fibers. Additionally, the temperature corresponding to the maximum reduction rate was also lower than for softwood fibers. Owing to their structure, softwood fibers were easy to discompose. As the temperature was raised higher than $400{ }^{\circ} \mathrm{C}$, because the $\mathrm{BC}$ fibers had an ultra-fine network structure and high purity, they were more likely to form a graphite structure. Therefore, the final weight of BC fiber was about $20 \%$ of its original weight, while the softwood fiber was only $15 \%$, more or less. Continuing to increase the temperature further, fibers' weight hardly changed.

\section{Analysis of Fibers' Morphology}

As shown in Table 1, the BC fibers were shorter than the softwood fibers. The arithmetic average fiber length $(\mathrm{L}(\mathrm{n}))$ was $0.69 \mathrm{~mm}$, which is considered short fiber in the papermaking industry. A typical BC fiber width has been reported to be less than $10 \mu \mathrm{m}$ (Liu et al. 2007), but in the present work the observed width was greater. The bacterial cellulose wet membrane did not spread into single fibers, but rather dispersed in the form of fiber ribbons, the surfaces of which were covered with much smaller "fibers". Therefore, the width distribution of BC fibers was closer to that of softwood fibers. Such a combination would be expected to improve the intertwining among fibers. What's more, fiber kink index of a typical fiber indicates that the fiber wall was damaged or turned by an external force (Lai et al. 2003). In BC fiber, there is no fiber wall, so the presence of any kinks has to be attributed to damage caused by the dispersion process. Its kink index was relatively small, indicating that the BC fiber did not incur major damage, and the dispersion method was proper.

Table 1. Fiber Analysis Results of Kajaani FS300

\begin{tabular}{|c|c|c|c|}
\hline & \multicolumn{3}{|c|}{ Fiber length (mm) } \\
\hline & $\mathrm{L}(\mathrm{n})$ & $\mathrm{L}(\mathrm{l})$ & $\mathrm{L}(\mathrm{w})$ \\
\hline Bacterial fibers & 0.69 & 1.35 & 2.05 \\
\hline Softwood fibers & 1.05 & 2.18 & 2.85 \\
\hline
\end{tabular}

$\mathrm{L}(\mathrm{w})$ : length weighted average fiber length

$L(w w)$ :weight weighted average fiber length

\begin{tabular}{|c|c|c|c|}
\hline & Fiber width(um) & Fiber curl index (\%) & $\begin{array}{c}\text { Fiber kink } \\
\text { index }(1 / \mathrm{m})\end{array}$ \\
\hline Bacterial fibers & 19.87 & 23.66 & 187.16 \\
\hline Softwood fibers & 31.64 & 23.05 & 790.54 \\
\hline
\end{tabular}

\section{The SEM Analysis of Sheets}

As Fig. 6 shows, sheets having 100\% softwood fiber had large gaps between the fibers. The fibers were not intertwined closely. With the addition of $5 \% \mathrm{BC}$ fibers in the sheet, although BC fibers' length was short, it was able to fill in among the softwood fibers and improve the density of the randomly woven structure. Figure 7 shows that BC played a bridging role among softwood fibers, owing to its much smaller fibers on the surface. As the bonding among fibers was increased, the strength of the sheets improved. 


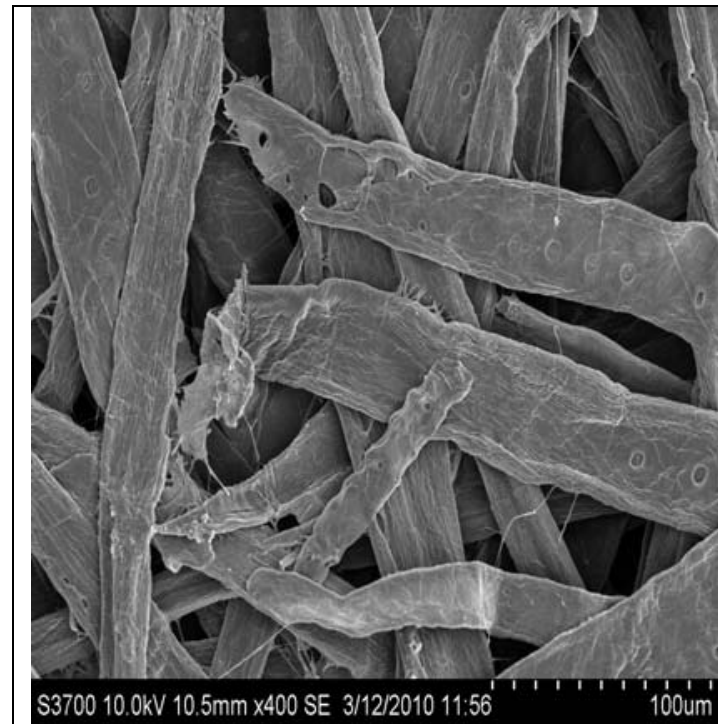

Fig. 6. Sheet with $100 \%$ softwood fibers

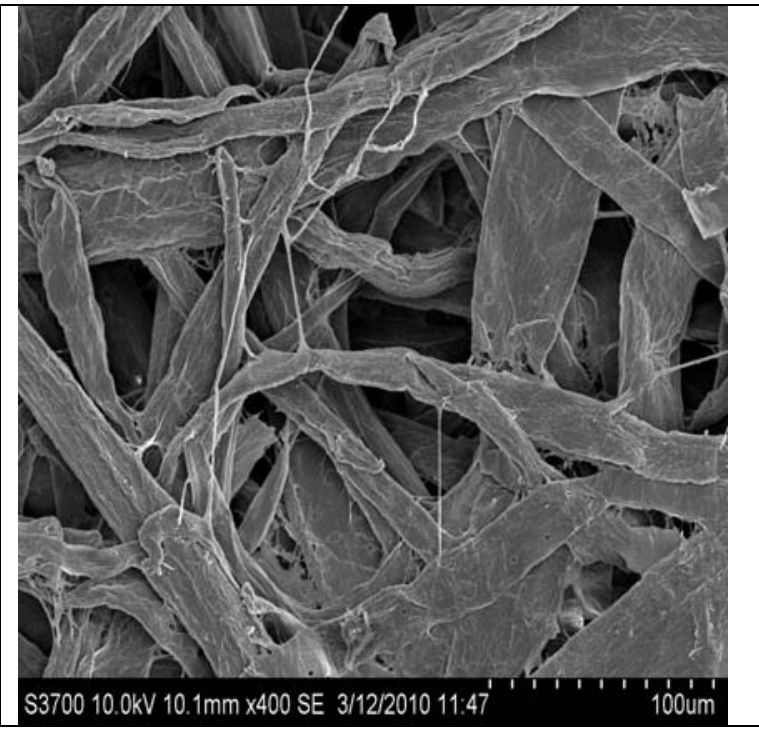

Fig. 7. Sheet with $5 \%$ BC fibers

\section{Effects of BC Fibers on Sheet Properties}

In this part, the physical properties of sheets with adding different dosage of $\mathrm{BC}$ fibers are discussed. BC fibers were obtained after different dispersing times.

As Figs. 8 to10 show, the tensile index, tear index, and burst index properties of the sheet increased with an increase in the $\mathrm{BC}$ fibers dosage. In particular, when the dosage of $\mathrm{BC}$ fibers was $5 \%$, the tear index and burst index values nearly doubled. Adding BC fibers was shown to improve the sheet's properties, and the optimum dispersing time of bacterial cellulose wet membrane was 3 minutes. At this dispersing time, BC fibers' morphology was suitable for forming sheets. The strength of bacterial cellulose wet membrane was high. When the dispersing time was 1.5 minutes, it formed a large number of fiber fragments. Such fragments could not achieve a good combination with softwood fibers, so the properties of sheets were decreased. However, when the dispersing time was 5 minutes, many fragments were scattered into small fibers, and in the process of forming sheets a large proportion of them were lost in the water. As a consequence, the level of BC fibers retained in the sheet was low, and the properties of sheets decreased slightly.

As Fig.11 shows, the stiffness of paper increased when adding BC fibers in the sheet. The bacterial cellulose wet membrane was scattered into BC fibers. The fibers removed moisture in the process of drying the sheets. Dried BC fiber was hard, and its elastic modulus was large, so it improved the paper's stiffness. When the dispersing time was 1.5 minutes, the stiffness properties were greater than for other periods of dispersion. Therefore, the fragments played a more important role in stiffness than did the small fibers. 


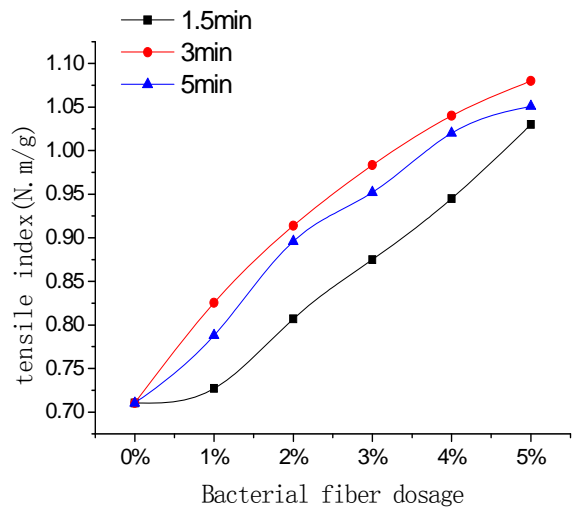

Fig. 8. Effects of BC fiber on the tensile index of paper

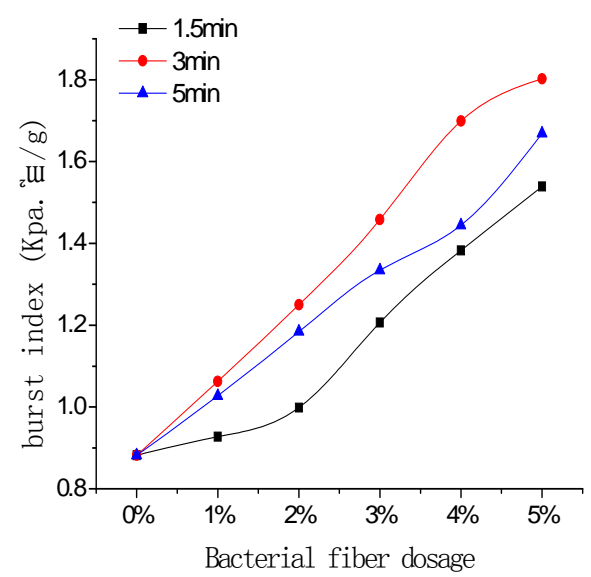

Fig. 10. Effects of $B C$ fiber on the burst index of paper

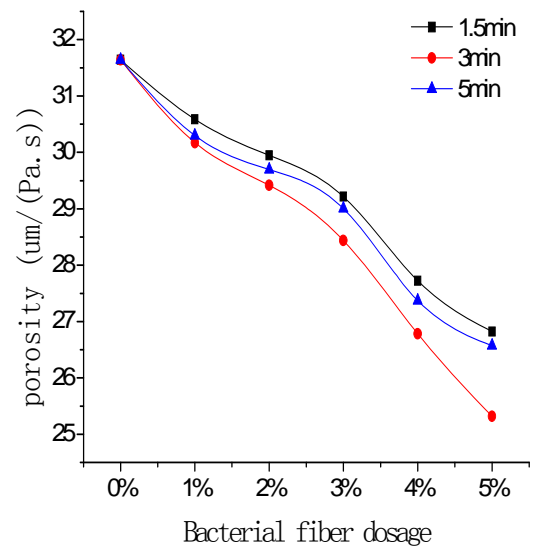

Fig. 12. Effects of $B C$ fiber on the porosity property of paper

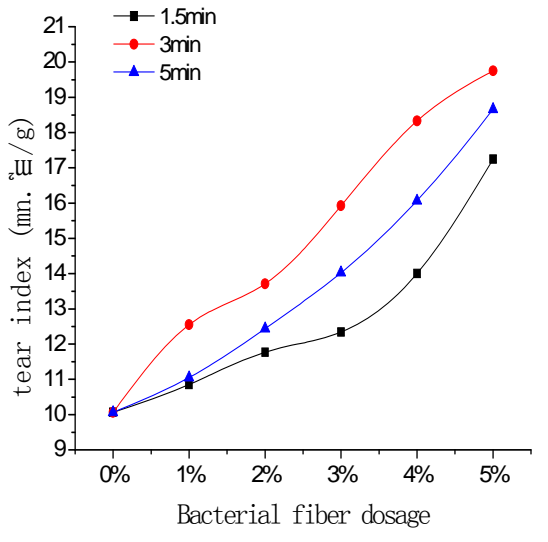

Fig. 9. Effects of $B C$ fiber on the tear index of paper

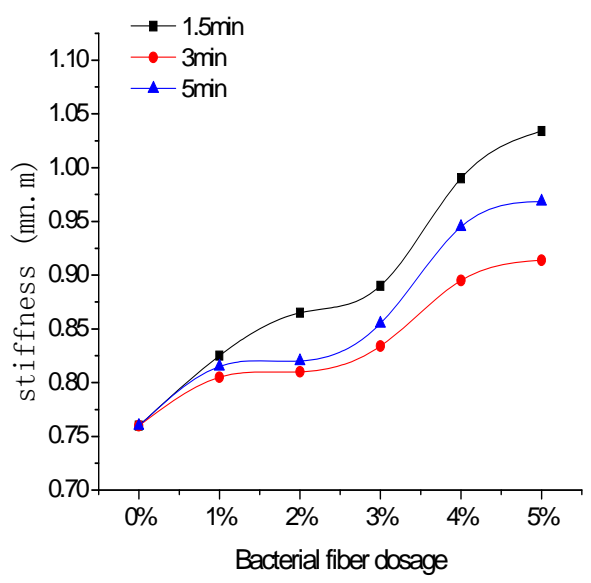

Fig. 11. Effects of $B C$ fiber on the stiffness of paper

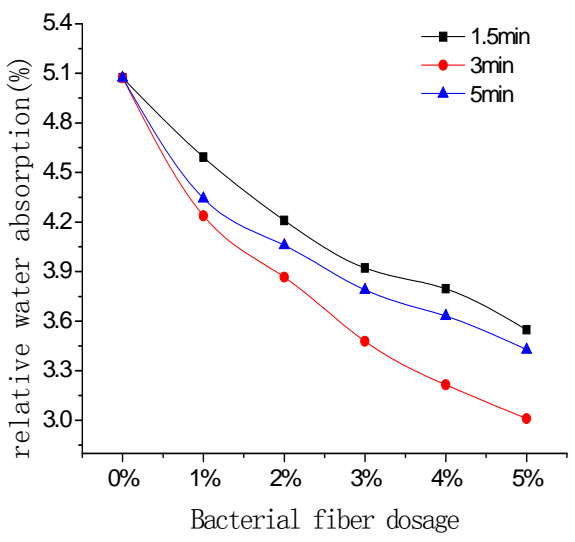

Fig. 13. Effects of $B C$ fiber on the relative water absorption property of paper 
As shown in Fig. 12, the porosity of the sheets decreased with an increasing dosage of BC fibers. In particular, when the dispersing time was 3 minutes, the porosity was much lower. That is to say the fibers in the sheet intertwined more closely and the spaces among fibers were small.

The sheets' relative water absorption was reduced along with the rising dosage of BC fibers. As shown in Fig. 13, although the initial moisture content of bacterial membrane was high, after scattering and drying, the ability of BC fibers to absorb moisture decreased. In the process of dispersing, hydrogen bonds between fibers in the bacterial cellulose wet membrane were cut off, forming BC fibers. An ultra-fine network structure was partly destroyed. The ruptured hydrogen bonds hardly formed new hydrogen bonds with other water molecule to make ultra-fine network structure. Therefore, as the dosage of BC fibers became larger, the ability of the sheet to absorb water decreased, and the material absorbed little moisture. In other words, the sheet's relative ability to absorb water declined when the content of BC fiber increased.

\section{CONCLUSIONS}

1. A morphological analysis of bacterial cellulose (BC) fibers and softwood fibers showed that there are many differences between them. The surface of BC fibers is constituted by entangled fibrils, while softwood fiber has a spindle structure. The length of dispersed BC fibers was shorter, but the width, curl index, and kink index were closer to those of softwood fibers.

2. FT-IR spectroscopy analyses showed that bacterial fibers and softwood fibers have similar compositions, while TGA analysis showed that bacterial fibers have a special structure. Based on SEM images, one can conclude that BC fibers and softwood fibers can form a good combination. BC fibers fill in among the softwood fibers in the sheet.

3. BC fibers improved the properties of the sheet, especially when the dispersing time of the bacterial membrane was 3 minutes. The sheet properties rose obviously with increasing dosage of BC fibers. In sum, the BC fibers can improve sheets’ physical properties.

\section{REFERENCES CITED}

Jonas, R., and Farah, L. (1998). "Production and application of microbial cellulose,”Polym. Degrad. Stab. 59, 101-106.

Martins, I. M. B., Magina, S. P., Oliveira, L. Freire, C. S .R., Silvestre, A. J. D, Neto, C. P., and Gandini A. (2009). "New biocomposites based on thermoplastic starch and bacterial cellulose,” Composites Science and Technology 69, 2163-2168.

Sakairi, N., Asano, H., Ogawa, M., Nishi, N., and Tokura, S. (1998). “A method for direct harvest of bacterial cellulose filaments during continuous cultivation of Acetobacterxylinum,” Carbohydr. Polym. 35, 233-237. 
Vandamme, E. J., Baets, S. D., Vanbaelen, A., Joris, K., and De Wulf, P. (1998). "Improved production of bacterial cellulose and its application potential," Polym. Degrad. Stab. 59 (1998) 93-99.

Budhiono, A., Rosidi, B., Taher, H., and Iguchi, M. (1999).“Kinetic aspects of bacterialcellulose formation in nata-de-coco culture system,"Carbohyd. Polym. 40, 137-143.

Masaoka, S., Ohe, T., and Sakota, N. (1993)."Production of cellulose from glucose by Acetobacterxylinum,”J. Ferm. Bioeng. 75, 18-34.

Keshk, S. (2006). "Physical properties of bacterial cellulose sheets produced in presence of lignosulfonate,” Enzyme and Microbial Technology 40, 9-12.

Sokolnicki, A. M., Fisher, R. J., Harrah, T. P., and Kaplan, D. L. (2006). "Permeability of bacterial cellulose membranes,” Journal of Membrane Science 272, $15-27$.

Wong, S.-S., Kasapis, S., Fang, F., and Tan, M. (2009). "Bacterial and plant cellulose modification using ultrasound irradiation,” Carbohydrate Polymers 77, 280-287.

Ramana, K. V., Tomar, A., and Singh, L. (2000). "Effect of various carbon and nitrogensources on cellulose synthesis by Acetobacterxylinum,” World J. Microbiol. Biotechnol. 16, 245-257.

Singh, L., Ramana, K. V., Banerjee, S., Dubey, V., and Chauhan, R S. (1996). "Studies on bacterial cellulose membrane production and its structural properties,” In:

Proceedings of the IMS XIV National Symposium on Membranes in Chemical and Biochemical Industries, IIT Delhi, India, 16-17 February, 1996, p. 31.

Dubey, V., Saxena, C., Singh, L., Ramana, K. V., and Chauahan, R. S. (2002). "Pervaporation of binary water-ethanol mixtures through bacterial cellulose membrane,” Sep. Purif. Technol. 27, 163-171.

Evans, B. R., O’Neill, H. M., Malyvanh, V. P., Lee, I., and Woodward, J. (2003). "Palladium-bacterial cellulose membranes for fuel cells," Biosens. Bioelectron. 18, 917-923.

Gindl, W., and Keckes, J. (2004). “Tensile properties of cellulose acetate butyrate composites reinforced with bacterial cellulose,” Composites Science and Technology 64, 2407-2413.

Basta, A. H., and El-Saied, H. (2009). "Performance of improved bacterial cellulose application in the production of functional paper," Journal of Applied Microbiology 107, 2098-2107.

Liu, S.-X., and Li, C.-F. (2007). Bacterial Cellulose, China Agricultural University Press, 6.

Lai, Y., Xie, Y., and Wu, H. (2003). “Average fiber length and its instrumental measurement result analysis,” Paper Science and Technology 22(3), 35-37.

Article submitted: June 28, 2010; Peer review completed: Oct. 6, 2010; Accepted: Oct. 29, 2010; Published: Nov. 24, 2010. 